\title{
1 Biomediated synthesis of silver nanoparticles using Exiguobacterium
}

\section{2 mexicanum PR 10.6}

3

4 Aparna J. Padman, Janey Henderson, Simon Hodgson and Pattanathu K.S.M. Rahman*

5 School of Science and Engineering, Teesside University, Middlesbrough, TS13BA, UK.

6 *Author for Correspondence (Fax: 0044-1642-384669; Email: p.rahman@tees.ac.uk) 7

8 Abstract: The study reports the biomediated silver nanoparticle synthesis using the cell free 9 extract of a soil bacterium, Exiguobacterium mexicanum PR 10.6. The silver nanoparticle

10 samples were characterised using UV-Visible spectroscopy, Energy Dispersive Spectroscopy (EDS), Fourier Transform Infrared Spectroscopy (FTIR), and Transmission Electron Microscopy (TEM). The results show that silver nanoparticle of size range 5-40 nm could be synthesised using this method. The extracellular polymeric substance (EPS) plays the critical role in the silver ion reduction and nanoparticle stabilisation, when using the cell free extract. The results suggest that the biomediated synthesis using Exiguobacterium mexicanum PR 10.6 could be an effective eco-friendly rapid method for silver nanoparticle synthesis in an hour.

Key words: Biomediated synthesis, Exiguobacterium mexicanum, Silver nanoparticles

\section{Introduction}

Nanomaterials, which are defined as materials with at least one dimension roughly between 1 and $100 \mathrm{~nm}$. The characteristic features of nanoparticles such as their high volume/surface ratio, surface tailorability, improved solubility and multifunctionality open many new possibilities for biomedicine (Gao and Xu 2009). The optical, electronic and electrical 
properties of nanoparticles are size dependent and various novel methods for the size controlled synthesis of silver nanoparticles are being developed (Li et al. 2006). The high energy requirement in physical methods of nanoparticle synthesis and the waste disposal problems in the chemical synthesis due to the heavy use of organic solvents, toxic reducing agents and capping agents are major demerits of the conventional nanoparticle synthesis (Xie et al. 2005). These factors have led to a demand for the development of more environmental friendly methods for the nanoparticle synthesis for sustainability. Biological synthesis of metal nanoparticles has been considered as one of the eco- friendly approaches for the synthesis of the metal nanoparticles (Vigneshwaran et al. 2007). These process in which materials are synthesised using biological agents such as ,bacteria (Juibari et al. 2011), fungi (Castro-Longoria et al. 2011), yeast (Kowshik et al. 2003), live plants (Gardea-Torresday et al. 2003), plant extracts (Hebbalalu et al. 2013; Sivaraj et al. 2014 ), enzymes (Kumar et al. 2007) and peptides from phage library (Naik et al. 2002).

In this study, we report the biomediated synthesis of silver nanoparticles using a novel strain Exiguobacterium mexicanum PR 10.6 isolated from metal contaminated soil samples of North East of England. The silver nanoparticles are characterised using UV- Visible Spectroscopy, Energy Dispersive Spectroscopy (EDS), Fourier Transform Infrared Spectroscopy (FTIR) and High Resolution Transmission Electron Microscopy (HRTEM).

Materials and methods

\section{Chemicals}

Silver nitrate (Sigma) was used as the metal precursor solution for silver nanoparticle synthesis. Nutrient broth (Oxoid) and Nutrient agar (Oxoid) were used for the growth and 
Biomediated synthesis of silver nanoparticle

53

54 The bacterial culture, Exiguobacterium mexicanum PR 10.6 was subcultured in $100 \mathrm{ml}$

55 nutrient broth and incubated at $30^{\circ} \mathrm{C}$ for $48 \mathrm{~h}$ in a rotary shaker (New Brunswick-Innova) at

$56150 \mathrm{rpm}$ and the culture was centrifuged using centrifuge (Thermo electron corporation -

$57 \mathrm{CR} 31)$ at $5,000(\mathrm{~g})$ for $10 \mathrm{~min}$ to separate the bacterial pellet from nutrient broth. The

58 bacterial pellet was suspended in $100 \mathrm{ml}$ sterile distilled water and mixed thoroughly. The

59 bacterial cell suspension was centrifuged at 14,000 ( $g$ ) for $20 \mathrm{~min}$. The supernatant was

60 filtered through $0.2 \mu \mathrm{m}$ filter (Whatman filter) and the filtrate was used for the silver

61 nanoparticle synthesis. In $90 \mathrm{ml}$ of the filtrate, $10 \mathrm{ml}$ of $10 \mathrm{mM}$ silver nitrate solution was

62 added. The reaction mixture was incubated at room temperature $\left(20 \pm 2^{\circ} \mathrm{C}\right)$.

63

64 Instrumental characterisation of biomediated silver nanoparticle sample

65

66 An aliquot of sample was taken at $1 \mathrm{~h}$ from reaction mixture and analysed in UV-Visible

67 Spectrophotometer (Jasco), using cuvette (Plastibrand). The wavelength scan measurement was performed between the wavelengths, 200 and $800 \mathrm{~nm}$ at resolution of $1 \mathrm{~nm}$ with a scanning speed of $0.1 \mathrm{~nm} / \mathrm{sec}$. The analysis in Energy Dispersive X-ray Spectroscopy (EDS;

70 Inca Penta) equipped with Scanning Electron Microscopy (SEM; Hitachi S-3400 N) at an 71 accelerating voltage of $20 \mathrm{KeV}$ was carried out using dried samples at $40^{\circ} \mathrm{C}$ and fixed on 72 carbon tabs and mounted on sample holders. The liquid sample $(100 \mu 1)$ were added on the 73 lacey grids (Agar) and air dried for 15 min and analysed in Transmission Electron

74 Microscopy (TEM; Jeol 4000 EX HREM) at voltage $400 \mathrm{KV}$ with vacuum of $4.5 * 10^{5}$ Torr.

75 The aliquot of sample was freeze dried (ThermoScientific-Heto PowerDry LL1500 and 
76 Fourier Transform Infrared Spectroscopy (FTIR) analysis (Thermo electronic corporation-

77 Nicolet 5700) was carried out using the between 400 and $4000 \mathrm{~cm}^{-1}$. The result was analysed 78 using OMNIC software.

79

80 Results

81

82

Biomediated synthesis of silver nanoparticle

83

84 The bacterial cell free filtrate when mixed with $1 \mathrm{mM}$ silver nitrate was initially colourless.

85 Within $10 \mathrm{~min}$, a gradual colour change was observed. In $30 \mathrm{~min}$, the colourless solution had 86 changed to a brown colour, which became intense after1 h (Fig 1-inset). This dark brown 87 colour is an indication of the formation of the silver nanoparticles (Bhainsa and D'Souza 88 2006).

89 Note 1: (Insert Figure 1)

90

91 Instrumental characterisation of the biomediated silver nanoparticles

92 The UV-Visible spectroscopy spectrum results of the samples after $1 \mathrm{~h}$ exhibited a peak at $93412 \mathrm{~nm}$ (Fig. 1) indicating the formation of silver nanoparticles. Silver nanoparticles 94 characteristically produce a peak in the region 350-450 nm (Mulvaney 1996). EDS analysis 95 of these particles confirmed that the sample contained predominantly silver (Fig 2). The 96 sample has other elements such as silicon, oxygen, phosphorus, chlorine, and calcium. The 97 transmission electron microscope (TEM) images (Fig. 3a) show that the silver particles are nanosize, typically less than $50 \mathrm{~nm}$ in diameter, being present in two size populations comprising smaller particles in the range $5-13 \mathrm{~nm}$ and larger particles in the range of 20-30.

100 Under higher magnification (Fig. 3b), the crystal lattice was evident, confirming the 
101

102

103

104

105

106

107

108

109

110

111

112

113

114

115

116

117

118

119

120

121

122

123

124

125

crystallinity of the nanoparticles. The FTIR spectrum obtained from the biomediated silver nanoparticle sample (Fig 4) exhibited major peaks at $3247\left(\mathrm{~cm}^{-1}\right), 2916\left(\mathrm{~cm}^{-1}\right), 1635\left(\mathrm{~cm}^{-1}\right)$, $1547\left(\mathrm{~cm}^{-1}\right)$ and $1051\left(\mathrm{~cm}^{-1}\right)$ indicating the presence of amides.

\section{Note 2: (Insert Figure 2, 3 and 4)}

\section{Discussion}

Biomediated synthesis of nanoparticles is an environment benign silver nanoparticle synthesis process The process helps to obtain nano structures with less defects and better short and long range ordering, as the a process is mainly driven by reduction of Gibb's free energy (Leela and Vivekanandan 2008). The bacterial based nanoparticle synthesis also has advantages such as easiness in downstream processing, genetic manipulation, short doubling time etc (Sastry et al. 2003). In the biomediated silver synthesis, the colour change of the solution after adding silver nitrate is the indication of the formation of nanoparticles (Fig. 1inset). The colour change of the solution can be attributed to the specific optical properties of the nanoparticles (Mulvaney 1996). The silver nanoparticles exhibit characteristic peaks between 350 - $450 \mathrm{~nm}$ due to Surface Plasmon Resonance (SPR) effects. This work demonstrated that the SPR at $412 \mathrm{~nm}$ (Fig. 1) was indicative of spherical nanoparticles without size variation (Mock et al. 2002).

The other elements (phosphorus, calcium, chlorine and silicon) identified in the EDS (Fig. 2) indicate the presence of biological matrix present in the sample. The silicon peak could have been attributed by the stub used for the analysis. The HRTEM images (Fig 3a) confirm that the particles are between 5 and $30 \mathrm{~nm}$ in diameter. The FTIR result of the sample (Fig.4) shows characteristic stretching vibrations of $\mathrm{N}-\mathrm{H}$ bonds in the region of $3247 \mathrm{~cm}^{-1}$. The 
126 intense peak at $1635 \mathrm{~cm}^{-1}$ could be the stretching vibrations of the Carbonyl group $(\mathrm{C}=\mathrm{O})$.

127 The combination of N-H deformation and C-N stretching vibrations attributes the peak of

$1281547 \mathrm{~cm}^{-1}$. The peak at $1051 \mathrm{~cm}^{-1}$ could be the stretching vibration $\mathrm{N}-\mathrm{H}$ bond. The aliphatic

$129-\mathrm{N}\left(\mathrm{CH}_{3}\right)_{2}$ groups in the sample are indicated by the absorption bands at the $2916 \mathrm{~cm}^{-1}$. The

130 peak pattern in the FTIR correlates to the absorption bands of the secondary amides and the-

$131 \mathrm{~N}\left(\mathrm{CH}_{3}\right)_{2}$ bond refers to tertiary amides (Simons 1978). The presence of amides is evidenced

132 as the indication of proteins in the sample (Sanghi and Verma 2009). The mechanism of

133 biomediated synthesis is not completely elucidated and there were several proposals for the

134 mechanism of nanoparticle synthesis. Gadd et al. (1989) had reported the accumulation of

135 silver using Pseudomonas stutzeri AG259, which was isolated from silver mine. The

136 mechanism of the intracellular synthesis of silver nanoparticles was related to the metal

137 resistance property of the organism against the toxicity of the metal. Schultze-Lam et al

138 (1996) had suggested that bacteria could precipitate an amount of metal equal to, or

139 exceeding their cellular weight. It could be an explanation for the extracellular synthesis of

140 metals.

141

142 In this study, the bacterial cell free extract is used for the silver nanoparticle synthesis

143 (Materials and Methods section) and it is suggested that the Extracellular Polymeric

144 Substance (EPS) play role in the silver nanoparticle formation. EPS are the microbially

145 produced organic compounds constitutes of polysaccharide, protein, nucleic acids, uronic

146 acids, lipids and functional groups such as carboxyl, phosphoric, amine and hydroxyl groups.,

147 Proteins have suggested playing key role in the biomediated synthesis of nanoparticles

148 (Sanghi and Verma 2009). Naik et al. (2002) had shown peptides from the phage library

149 could form silver nanoparticles and Kumar et al. (2007) demonstrated that the enzyme, 
reductases could perform metal nanoparticle synthesis. The carbohydrates are also reported to play role in the silver reduction (Vigneshwaran et al. 2006).

152

153 EPS is loosely attached to the bacterial cell surface. Adav and Lee (2008) had suggested that

154 high speed centrifugation can extract the soluble EPS to the solution. EPS contains charged

155 moieties and have adsorptive and adhesive properties. It serves as a natural ligand and

156 binding sites of metals (Bhaskar and Bhosle 2006; Comte et al. 2008). It is suggested that the

157 EPS of bacteria acts as the electron donor (Fig. 5) in the biomediated silver synthesis using

158 cell free extract of bacteria.

159

160 Note 3: (Insert Figure 5)

161

162 In the biomediated synthesis silver nanoparticle (Fig. 5), the silver nitrate ionises to silver

$\left.163 \mathrm{Ag}^{+}\right)$ions and nitrate $\left(\mathrm{NO}_{3}^{-}\right)$ions in the solution, followed by the reduction of the $\mathrm{Ag}^{+}$ions, 164 to metallic silver $\left(\mathrm{Ag}^{0}\right)$.

165

Ionisation

166

167

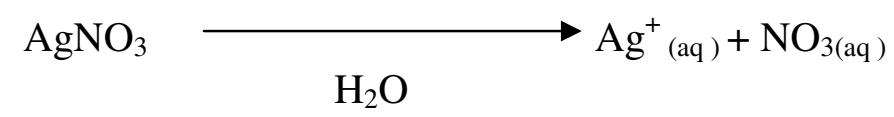

EPS are not active cells but have electrons (Laspidou and Rittmann 2002). The electrons

169 from the EPS could donate electrons to the $\mathrm{Ag}^{+}$ions, reduce them to metallic silver and

170 stabilise as nanoparticles.

171

172

Reduction

173

$\mathrm{Ag}^{+}(\mathrm{aq})+\mathrm{e}^{-} \longrightarrow \mathrm{Ag}^{0}$ 
175 This study reports an environmental friendly method for the synthesis of nanoparticles. EPS

176

177 bacterial cell filtrate.

178

179 Conclusion

180 This study focuses on the biomediated silver nanoparticle synthesis using the cell free extract of bacterium, Exiguobacterium mexicanum PR 10.6, isolated from the soil sample of the North East England. The instrumental characterisation results show that the cell free extract of Exiguobacterium mexicanum PR 10.6 could synthesise silver nanoparticle of size range 5-

$18440 \mathrm{~nm}$ at room temperature in $1 \mathrm{~h}$ incubation time. The study establishes that the biomediated 185 toxic chemicals or stringent conditions. It is assumed that the extracellular polymeric substance (EPS) present in the cell free extract plays the critical role in the silver nanoparticle reduction and stabilisation.

189

\section{Acknowledgments}

Authors would like to thank the Teesside University for the University Doctoral

Scholarship to Aparna Jaya Padman. The EPSRC is thanked for funding and the access to the

193 TEM instruments in Oxford Materials lab under the Materials Equipment Access Scheme, 194 Grant reference: EP/F01919X.

195

\section{References}


Bhainsa KC, D'Souza SF (2006) Extracellular biosynthesis of silver nanoparticles using

202 the fungus Aspergillus fumigates. Colloid Surface B 47:160-164

203

204

Bhaskar PV, Bhosle NB (2006) Bacterial extracellular polymeric substance (EPS): A

205 carrier of heavy metals in the marine food-chain. Environ Int 32:191-198

206

207

Castro-Longoria E, Vilchis-Nestor AR , Avalos-Borja M (2011) Biosynthesis of silver,

208 gold and bimetallic nanoparticles using the filamentous fungus Neurospora crassa.

209 Colloid Surface B 83:42-48

210

211

Comte S, Guibaud G, Baudu M (2008) Biosorption properties of extracellular polymeric

212 substances (EPS) towards $\mathrm{Cd}, \mathrm{Cu}$ and $\mathrm{Pb}$ for different $\mathrm{pH}$ values. J Hazard Mater

213 $151: 185-193$

214

215 Gadd GM, Laurence OS, Briscoe PA, Trevors JT (1989) Silver accumulation in $216 \quad$ Pseudomonas stutzeri AG259. Biometals 2:168-173

217

Gao J, Xu B (2009) Applications of nanomaterials inside cells. Nano Today 4:37-51

219

220 Gardea-Torresdey JL, Gomez E, Peralta-Videa JR, Parsons JG, Troiani H, Jose-

221 Yacaman M. (2003) Alfalfa sprouts: a natural source for the synthesis of silver

222 nanoparticles. Langmuir 19:1357-1361

223 

the synthesis of silver nanoparticles using plant extracts, enzymes, bacteria, biodegradable polymers, and microwaves. ACS Sustainable Chem. Eng 1, 703-712

227

Juibari MM, Abbasalizadeh A, Jouzani GhS, Noruzi M (2011) Intensified biosynthesis of silver nanoparticles using a native extremophilic Ureibacillus thermosphaericus strain. Mater Lett 65:1014-1017

231 Extracellular synthesis of silver nanoparticles by a silver-tolerant yeast strain MKY3.

$234 \quad$ Nanotechnol 14:95-100

235

236

Kumar SA, Abyaneh MK, Gosavi SW, Kulkarni SK, Pasricha R, Ahmad A, Khan MI

237 (2007) Nitrate reductase- mediated synthesis of silver nanoparticles from $\mathrm{AgNO}_{3}$.

Biotechnol Lett 29:439-445

239

Laspidou CS, Rittmann BE (2002) A unified theory for extracellular polymeric substances, soluble microbial products, and active and inert biomass. Water Res 36:2711-

242 2720

243

244 Leela A, Vivekanandan M (2008) Tapping the unexploited plant resources for the $245 \quad$ synthesis of silver nanoparticles. Afr J Biotechnol 7:3162-3165

246

247 Li Y, Kim NY, Lee EJ, Cai WP, Cho SO (2006) Synthesis of silver nanoparticles by 248 electron irradiation of silver acetate. Nucl Instrum Meth B 251:425-428 
250 Mock JJ, Barbic M, Smith DR, Schultz DA, Schultz S (2002) Shape effects in plasmon 251 resonance of individual colloidal silver nanoparticles. J Chem Phys 116:6755-6759

Mulvaney P (1996) Surface Plasmon Spectroscopy of nanosized metal particles.

254 Langmuir 12:788-800

255

Naik RR, Stringer SJ, Agarwal G, Jones SE, Stone MO (2002) Biomimetic synthesis and patterning of silver nanoparticles. Nat Mater 1:169-172

258

259

Sanghi R, Verma P (2009) Biomimetic synthesis and characterisation of protein capped silver nanoparticles. Bioresource Technol 100:501-504

261

Sastry M, Ahmad A, Khan MI, Kumar R (2003) Biosynthesis of metal nanoparticles using fungi and actinomycete. Curr Sci India 85:162-170

264

265

Schultze-Lam S, Fortin D, Davis BS, Beveridge TJ (1996) Mineralization of bacterial surfaces. Chem Geol 132:171-181

267

268

Simons WW (1978) The Sadtler handbook of Infrared spectra. Sadlter Research Laboratories Inc. Philadelphia and Heyden \& Son Ltd. London.

271 Sivaraj R, Rahman PKSM, Rajiv P, Narendhran S, Venckatesh R (2014) Biosynthesis and 272 characterization of Acalypha indica mediated copper oxide nanoparticles and evaluation of its 273 antimicrobial and anticancer activity, Spectrochim Acta A 129: 255-258 
Tamura K, Nei M, Kumar S (2004) Prospects for inferring very large phylogenies by

276 using the neighbor-joining method. P Natl Acad Sci USA 101:11030-11035

277

278 Vigneshwaran N, Nachane RP, Balasubramanya RH, Varadarajan PV (2006) A novel one 279 pot 'green' synthesis of stable silver nanoparticles using soluble starch. Carbohyd Res $280 \quad 341: 2012-2018$

281

282

283

284

Vigneshwaran N, Ashtaputre NM, Varadarajan PV, Nachane RP, Paralikar KM, Balasubramanya RH (2007) Biological synthesis of silver nanoparticles using the fungus

285

286

Xie J, Lee JY, Wang DIC, Ting YP (2007) Identification of active biomolecules in the 287 high yield synthesis of single crystalline gold nanoplates in algal solutions. Small 3:672-

288 682

289

\section{List of Figures captions}

291

292 Figure 1. UV- Visible spectrum of the sample from biomediated silver nanoparticle synthesis 293 using cell free extract of the Exiguobacterium mexicanum PR10.6. The inset represents the 294 visual observations of the sample. In both figure and inset; (A) Silver nitrate, (B) 295 Biomediated silver sample, (C) Cell free extract (blank). The spectrum scanning was 296 between wavelength $250-800 \mathrm{~nm}$. The biomediated sample (B) has turned to dark brown in 297 colour (inset) and shows the characteristic SPR peak at $412 \mathrm{~nm}$ in the spectrum 
299 Figure 2. Energy Dispersive Spectroscopy (EDS) spectrum of the biomediated silver 300 nanoparticle sample. The EDS spectrum shows the peaks for: chlorine $(\mathrm{Cl})$, calcium $(\mathrm{Ca})$, oxygen $(\mathrm{O})$, silicon $(\mathrm{Si})$, phosphorus $(\mathrm{P})$ and silver $(\mathrm{Ag})$

302

303 Figure 3. Transmission Electron Microscopy (TEM) image of the biomediated silver 304 nanoparticle sample. The Fig 3A shows the nanoparticle distribution at the maginification $30550000 X$. The Fig. 3b shows the magnified image of a single particle, at a magnification of 400000X. The scale bar in A is $50 \mathrm{~nm}$ and scale bar in Fig 3B is $5 \mathrm{~nm}$

Figure 4. Fourier Transform Infrared Spectroscopy (FTIR) spectrum. The spectrum shows peaks at $3247\left(\mathrm{~cm}^{-1}\right), 2916\left(\mathrm{~cm}^{-1}\right), 1635\left(\mathrm{~cm}^{-1}\right), 1547\left(\mathrm{~cm}^{-1}\right)$ and $1051\left(\mathrm{~cm}^{-1}\right)$. The peak locations correspond to the stretching and bending vibrations of the amides

312 Figure 5. The schematic representation of the biomediated synthesis of silver nanoparticle.

313 Silver nitrate $\left(\mathrm{AgNO}_{3}\right)$ ionises to silver ion $\left(\mathrm{Ag}^{+}\right)$and $\left[\left(\mathrm{NO}_{3}\right)^{-1}\right]$. The bacterial cell wall has 314 loosely extracellular polymeric substance (EPS; $几 \sim$ ). Some of EPS has charged moieties $315(-)$. The silver ion $\left(\mathrm{Ag}^{+}\right)$is reduced to metallic particle using the electron provided by extracellular polymeric substance ( $\Omega \sim)$. The extracellular polymeric substance $(\mathbf{O})$ forms 317 layer around the silver nanoparticles and stabilizes metallic silver as individual particles $318(\mathrm{AgNP})$ 


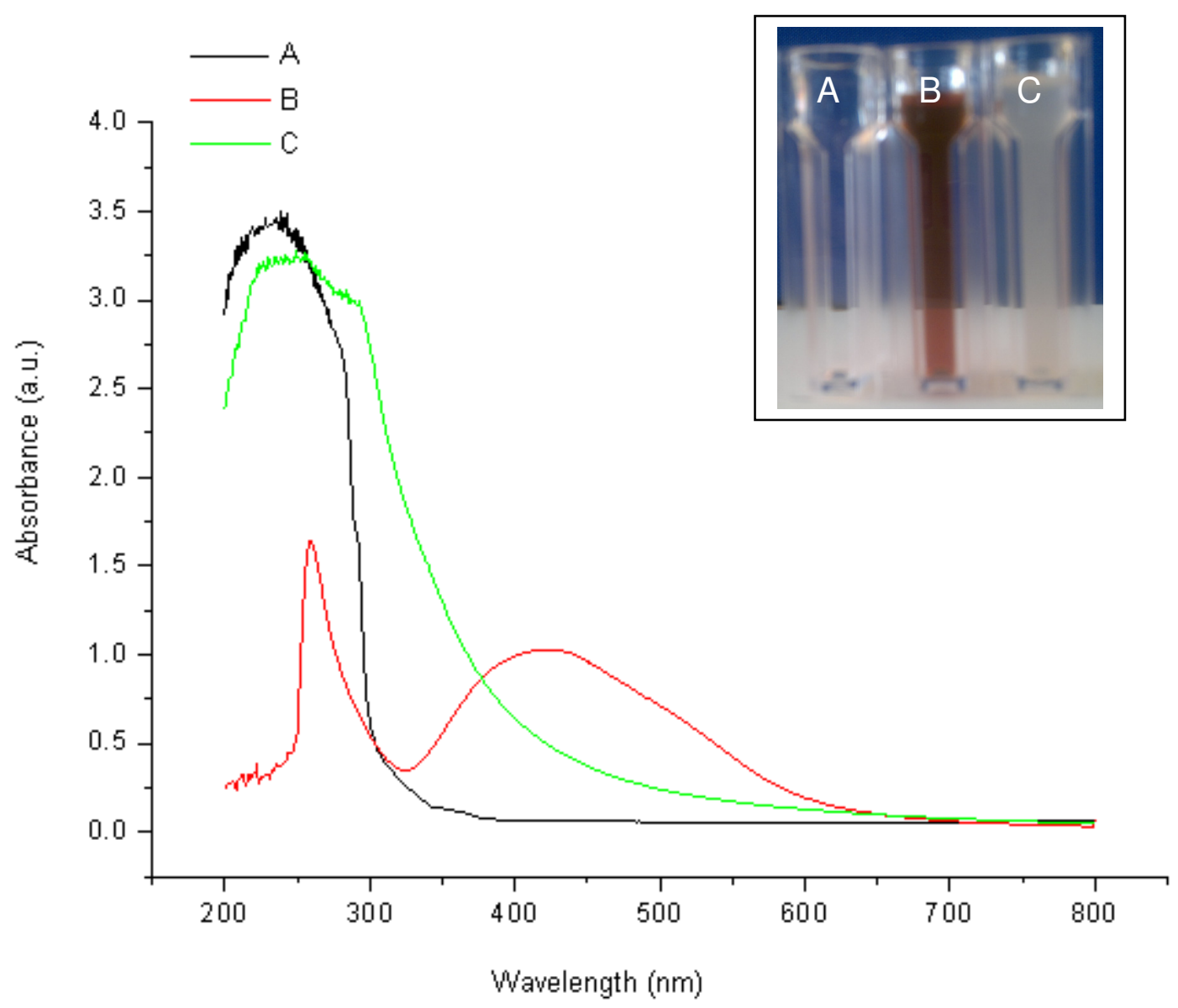

$330 \quad$ Figure 1 


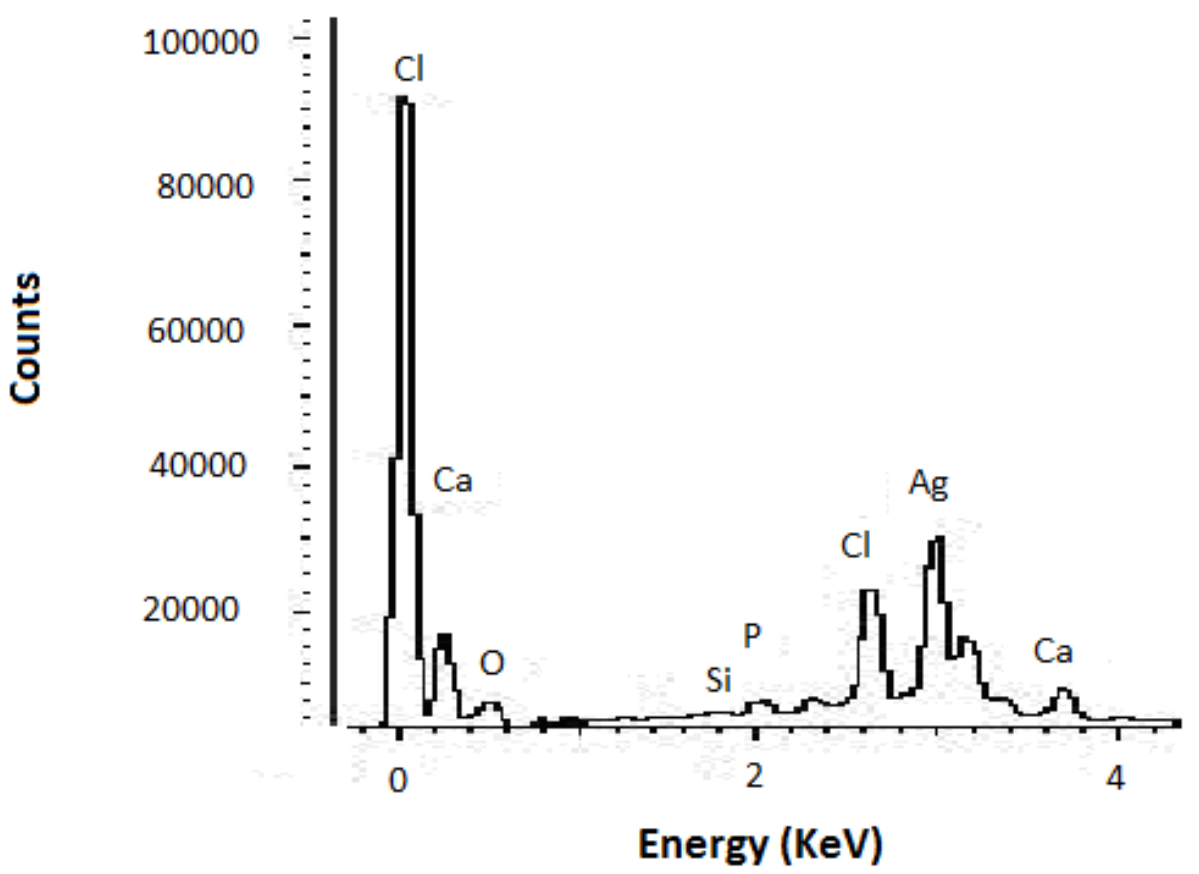

339

340

341

342

343

344

345

346

$347 \quad$ Figure 2

348

349

350

351

352 
354

355

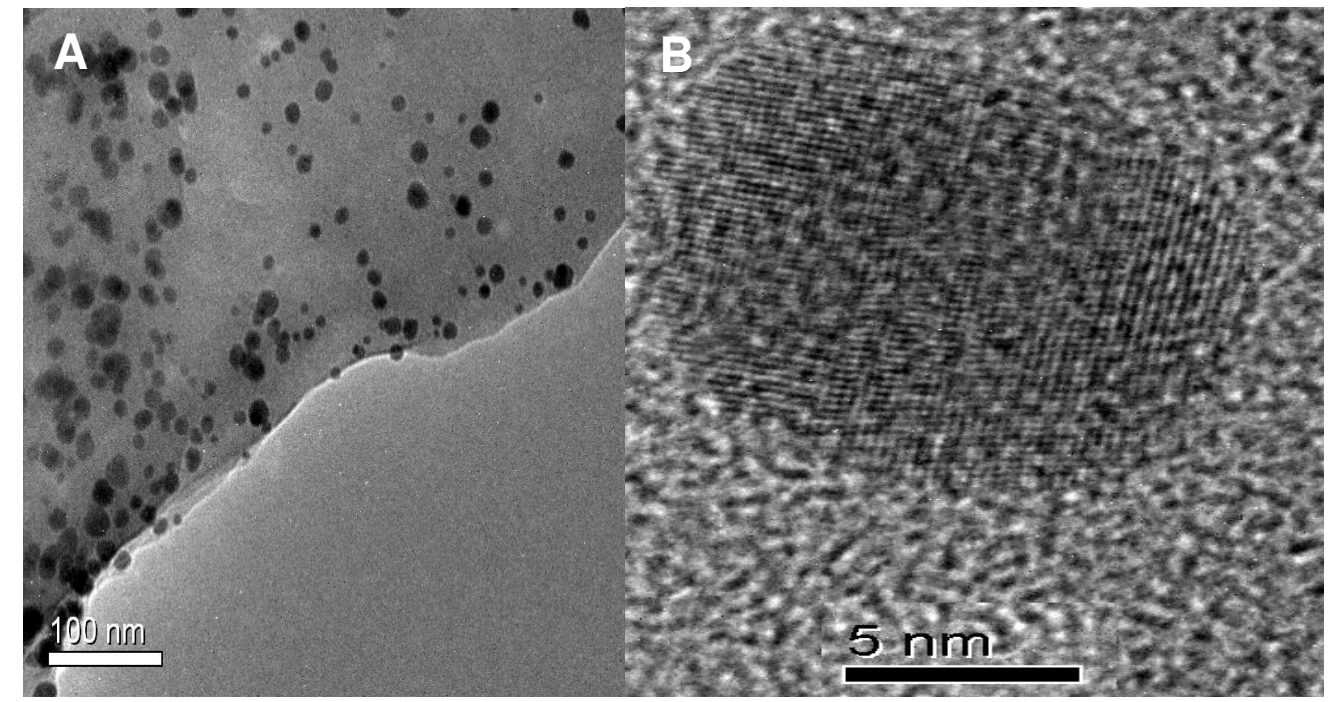

356

357

358

359

360

361

$362 \quad$ Figure 3

363

364

365

366

367

368

369

370

371 


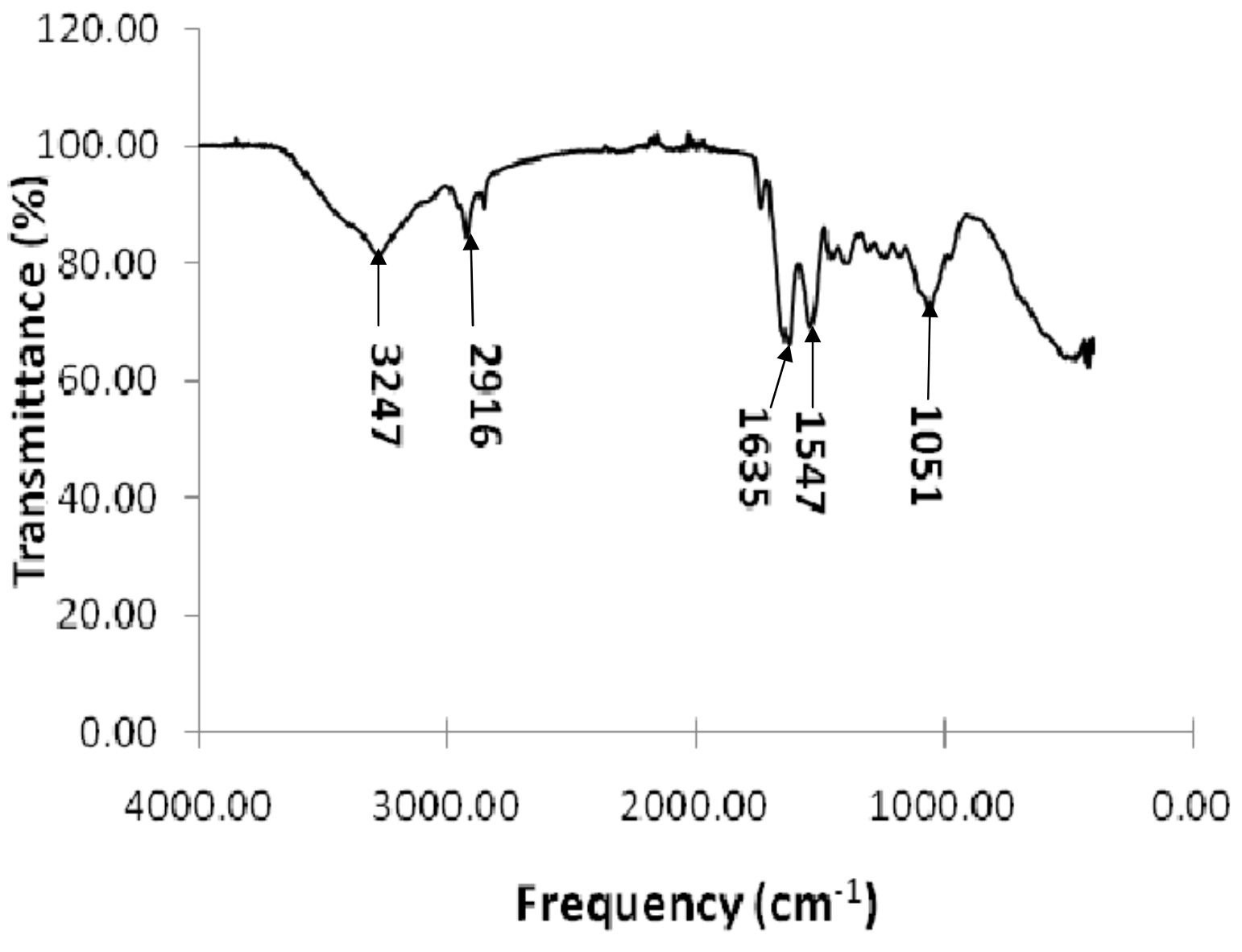

375

376

377

378

$379 \quad$ Figure 4

380

381

382

383

384 

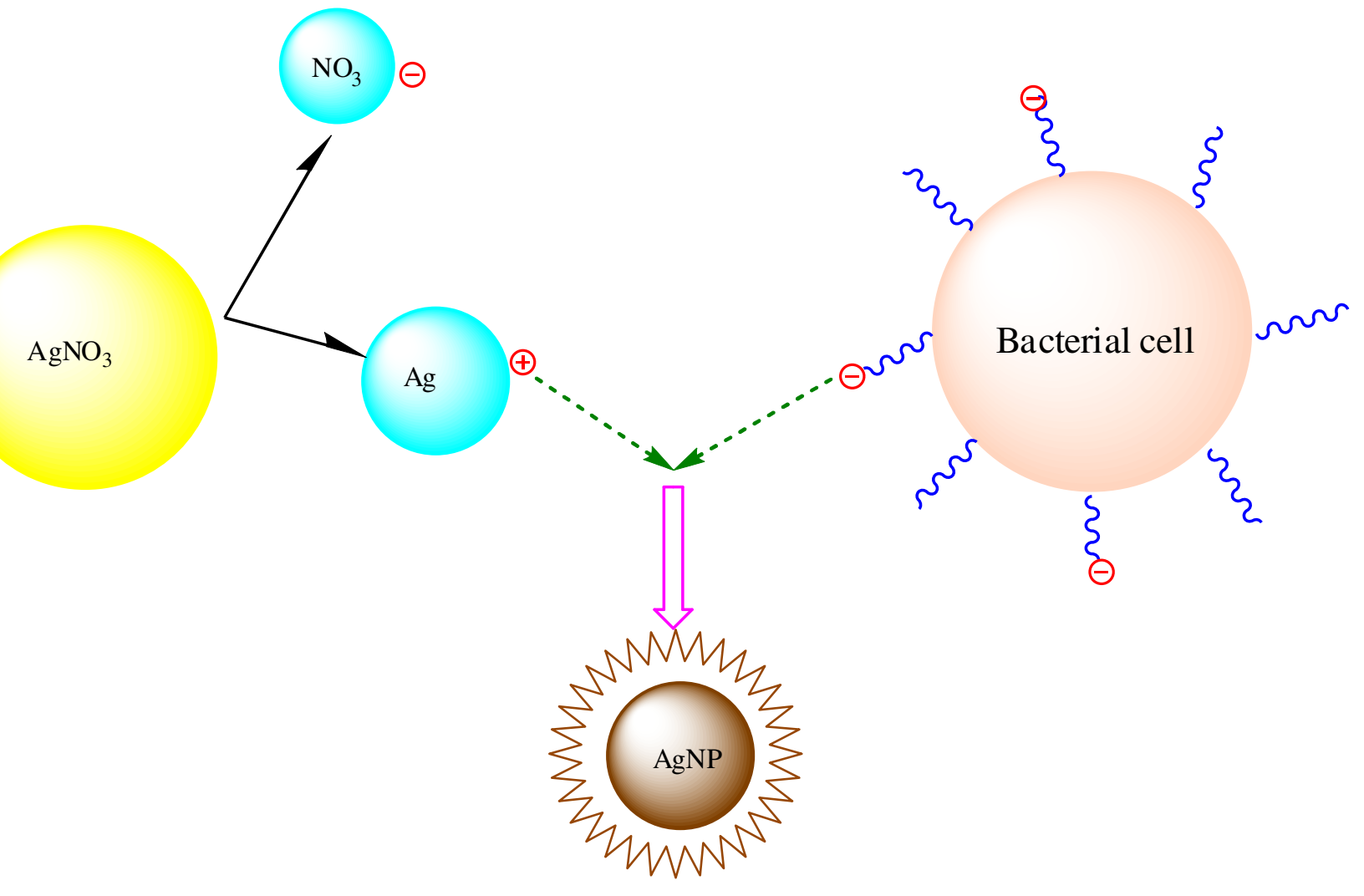

389

390

391

$392 \quad$ Figure 5 